\title{
FROM THE INSIDE
}

\section{Brave enough}

\author{
Thanh H. Neville* (1)
}

๑ 2021 Springer-Verlag GmbH Germany, part of Springer Nature

"There is always light, if only we're brave enough to see it. If only we're brave enough to be it."

\section{- Amanda Gorman}

So many thoughts ran through my head as I donned personal protective equipment (PPE) outside of the patient's room. The patient was an unvaccinated, previously healthy 55-year-old male who had now been in the hospital for nearly 4 weeks with respiratory failure due to coronavirus disease 2019 (COVID-19). I had first met him early in his hospitalization, when he was admitted to our intensive care unit (ICU) on maximum high-flow oxygen and saturating $90 \%$ during his good moments. He wanted to leave against medical advice because his plan was to obtain "vitamins" from the hospital and return home. He had refused intubation under any circumstance, expressed doubt over his COVID-19 diagnosis, and accused the medical team of wanting to intubate him for financial gain. Over the phone, his adult children echoed these sentiments and cited several sources of "research" suggesting that hospitals get paid an extra $\$ 20,000$ for every patient that dies after intubation.

He had been admitted to the ICU the day before I took over the service and as I listened to the sign-out, my blood boiled. This patient would not be the first unvaccinated and misinformed patient with COVID-19 that I took care of. These cases were frustrating, time-consuming, and frankly, a slap in the face. The current attending had placed the patient on a medical hold because of his questionable capacity, given the failure to understand that leaving the hospital would likely result in death. While this decision was supported by an Ethics consultation, I questioned whether misguided dogma was equivalent to the lack of capacity. But my colleague instead spent hours preventing him from leaving, just as I probably would

\footnotetext{
${ }^{*}$ Correspondence: tneville@mednet.ucla.edu Department of Medicine, Division of Pulmonary, Critical Care, and Sleep Medicine, David Geffen School of Medicine, UCLA, 43-229 CHS, Box 951690, Los Angeles, CA 90095-1690, USA
}

have, because "I did not do all of this medical training to watch a guy drop dead in our hospital hallway."

When I walked in, he continued to desaturate easily when speaking and with any movement. His imaging showed extensive subcutaneous emphysema and pneumomediastinum. I again explained his diagnosis, the risks and benefits of intubation, and that we only put patients on mechanical ventilation when the alternative was death. I placed his hand on his chest so that he could palpate his own crepitus. The conversation took over an hour, and though he remained skeptical of his diagnosis and prognosis, he agreed to remain hospitalized and be full code if he were to become unconscious. I took what I could get.

Six days later, he complained of chest pain and was now saturating in the 80's despite maximum oxygen support. His chest X-ray showed a new pneumothorax. I told him it was time. His son was placed on speaker phone as my colleagues and I set up for intubation and chest tube placement.

The conversation with his son took everything I could give and more.

His son did not believe the procedure was emergent. He demanded answers to questions that had already been answered multiple times. "What is his chance of surviving without the ventilator?" "How is this ventilator any different from what he is already getting?" He told us he had done his research and "knew a lot about ventilators". He criticized us for having said that his father needed intubation on admission, when "he's done fine" for several days now. He continued to talk in circles as his father's oxygen dipped. He then said, "I'm going to call my brother and I'll call you guys back with a decision." I lost that last tiny ounce of patience I had been holding on to.

"YOU GO DO THAT AND I'M GOING TO WALK OUT OF THIS ROOM AND WATCH YOUR FATHER DIE!" I shouted. As soon as the words left my mouth, I regretted them. His son faltered. His voice broke as he 
said, "Do what you have to." We intubated the patient and put in a surgical chest tube. We then paralyzed and proned him to oxygenate him. I worked methodically, placing all my feelings behind a wall of professionalism until I finally finished.

I walked out of the room shaking. It was nearly $9 \mathrm{pm}$. I stared at the crash cart I had told the team to drag over, just in case. I met the eyes of my tired nurses, many whom had stayed through shift change to help. They shook their heads in exasperation at our new normal. I saw their pity for me, and I knew I must have looked as defeated as I felt. I avoided the gaze of my trainees, wondering how I could justify this as a teachable moment.

I managed to drive home calmly but fell sobbing into my husband's arms that night. All the reasons I became a doctor seemed to be vanishing into thin air. "To use clinical knowledge and skills to help those in need"-never had I imagined that this would include pleading with patients and families as they cast doubt on every word. "To help people get well, but if not, facilitate a peaceful death" - we were accused of wanting bad outcomes for the very patients we wanted to help, of lying and making decisions based on financial motivation. "To connect and empathize with people during their darkest moments"I had yelled at and threatened a son that I was going to watch his father die. I was ashamed of this.

I realized that my patients' acknowledgement of my efforts mattered to me, that I needed them to believe in my good intentions. Throughout the pandemic, my commitment to patient care had never wavered. I never hesitated to commit long hours to patient care, to spend untold amounts of time with highly infectious patients, to sacrifice aspects of my personal life and quarantine away from my family. But I had also never doubted that patients knew my intentions and appreciated my efforts. This appreciation had always been a crucial part of the light that I see in the darkness of this pandemic.

Now, I was drained of all my energy, patience, and empathy. I was just empty-I had given everything I had and was only left with the question of why we were doing all this.

I rotated off the ICU service the next day but the coming weeks led to more questions than answers. I spent hours thinking about what I would have done if I had not been able to convince the patient and family to consent to medical care. Given the medical hold, would I really sedate and intubate without consent? And if the medical hold were removed, could I just watch the patient die? My chronic insomnia worsened. One night I dreamt the current ICU team missed an enlarging pneumothorax on a chest X-ray. I got out of bed at $3 \mathrm{AM}$ and logged into the electronic medical record to make sure this was not the case.

Now 3 weeks had passed since that horrendous day and I was standing outside his room. I was relieved to learn that he was extubated and transferred out of the ICU to the general floor. His chest tube had been removed and he would soon be discharged on a couple liters of oxygen. I was not on service, and even as I stood outside his room, I was not sure why I needed to see him-only that I did. Would he remember me? Would he mention the shouting match between myself and his son? Would he still think that he had "something else, not COVID-19"? Would he be indifferent? I gowned up and walked in. He was sitting in a chair and his eyes met mine.

He burst into tears. All the reasons I became a doctor came crashing back to me. I rushed over to kneel by his side, held his hand, and told him that everything was going to be ok. He thanked me for my care and told me that his family were all vaccinated now. My eyes must have expressed disbelief because he reached for his phone to show me pictures of them with Band-Aids on their arms.

These past few months of the pandemic have challenged physicians in ways that many of us had never experienced or anticipated. In this era of misinformation, we are being asked to trust in our own willingness to fight for our patients despite their lack of trust in usto not only SEE the light, but BE the light. As I got up to leave the patient's room, he quickly added "I think the vitamins I took helped too!" I faltered for an imperceptible moment before deciding that this was good enough, smiled, and nodded. I was still smiling as I walked away from the room, deciding that yes, I am indeed, brave enough.

\section{Declarations}

Conflicts of interest

I have no conflicts of interest to disclose.

\section{Informed consent}

This essay is non-fiction and I have obtained consent from the patient and his family to publish his story.

\section{Publisher's Note}

Springer Nature remains neutral with regard to jurisdictional claims in published maps and institutional affiliations.

Received: 14 October 2021 Accepted: 3 November 2021

Published: 17 November 2021 